EPiC Series in Language and Linguistics
Volume 2, 2017, Pages 256-264
Professional and Academic Discourse:
an Interdisciplinary Perspective

\title{
A Description of Asynchronous Online Discussions in Higher Education ${ }^{1}$
}

\author{
Francisco Javier Fernández Polo and Mario Cal Varela \\ Universidade de Santiago de Compostela \\ xabier.fernandez@usc.es, mario.cal@usc.es
}

\begin{abstract}
This study provides a preliminary characterisation of asynchronous online discussions as a learning tool in higher education (Garrison 2003; Ho \& Swan 2007). Our materials consist of the written record of 16 online discussions, totalling circa 165,000 words, from a one-semester course on general English-Spanish-English translation. The participants are second-year students from different nationalities, mostly Spanish, using Spanish and less frequently Galician as lingua francas. We start by describing the various situational factors surrounding the events (including the role of the discussions in the course, the variety of participants and the nature of their relationship), which may explain some highly recurrent language and organisational features encountered in the resulting texts. Secondly, using Antconc, we carry out an exploratory analysis of the lexical and collocational patterns of the exchanges. The findings reveal a very strong interactive component (Herring 1999, Condon \& Čech 2010), with two dominant functions, the creation of affiliation and the prevention of conflict. The analysis shows a widespread use of praise, hedging and other forms of politeness in the posts, and, more generally, a clear concern for the interests of other participants in the discussion and an effort to acknowledge their voices. In the paper, we also look into the evolution of the exchanges over the time-span of the course by focusing on one case study. The analysis reveals the progressive crystallisation of the genre in the student's interventions, a process which involves a clear evolution from a rather tentative kind of post, mostly monologic, informational and author-centred, to a progressively longer post with a more complex structure, and especially a heightened awareness of the dialogic and multi-party nature of the exchanges (Herring 1996). The results of the study may have considerable pedagogical interest. We believe that computer-mediated communication (CMC), including asynchronous online discussion forums, is bound to play an increasingly significant role in the future of higher education.
\end{abstract}

\footnotetext{
${ }^{1}$ The research reported in this article was funded by the Spanish Ministry of Economy and Competitiveness (grant FFI201564057-P). This grant is hereby gratefully acknowledged.
} 


\section{Introduction}

Computer-mediated-communication (CMC) has become a crucial element of present-day education at all levels, and particularly so in tertiary education, where students are increasingly involved in collaborative learning experiences in which they must plan research, exchange information, discuss viewpoints and, in general, co-construct their learning. One form of CMC, the discussion forum, is gaining popularity in Higher Education (HE).

Electronic forums have a number of defining features (Biber \& Conrad 1999). First, they are a form of asynchronous online communication, which means that, like e-mails, they are more finalized respect spelling, punctuation and grammar rules - than other online genres like chats or instant messaging. And second, unlike other similarly asynchronous forms of CMC (e.g. e-mails), they are multiparty communicative events. Participants in a forum share some kind of interests: a technology, a hobby, a health issue, etc., and organize forums in threads or thematic sequences consisting of individual posts.

Asynchronous online discussions have been found to offer a number of educational affordances, among which is convenience, the fact that learning can be done anytime, anyplace (Ho \& Swan 2007). This flexibility is in line with developments in HE, in particular, with the increasing demand for online courses, MOOCs, etc., and given that the process of globalization of tertiary education and, consequently, the boom of online education seems to be here to stay, the role of CMC and of asynchronous online discussions in particular has a bright prospect ahead as a learning tool.

Students perceive online discussions as more equitable and more democratic than classroom discussions. Everybody can have a voice, irrespective of status or power. No one dominates, not even the instructor (Swan \& Shih 2005), and students who are shy or need more time to articulate their thoughts tend to find this mode of participation more suitable and fair. Actually, this bias-free and egalitarian character is a widely praised (but also widely disputed) advantage of Internet communication in general.

Compared to other forms of academic writing, discussion forums are less formal. They are a form of hybrid communication (Biber \& Conrad 2009), sharing features of both written and spoken language (Ho \& Swan 2007). Both students and instructors have the necessary time to ponder their writing and make sure that it is properly relevant and concise, well organized and free from language mistakes. At the same time, messages also retain a certain dialogic character, being more personal and informal than other forms of academic writing.

Being asynchronous, online forums foster a culture of reflection, on others' ideas as well as one's own, which is essential for deep, meaningful and lasting learning (Ho \& Swan 2007). One major strength of asynchronous online communication is "the permanent and precise nature of the communication that encourages if not necessitates reflection"; the resulting "dialogic writing process is not so spontaneous and fleeting as verbal communication": it naturally leads students to a systematic construction of meaning that involves "planning, structure, and the facilitation of the discourse toward a clear goal.” (Garrison 2003, 55-6)

At the core of the properties of asynchronous online discussions is the ability to provide collaborative learning experiences (Garrison 2003). Such experiences represent a radical change vis-àvis traditional pedagogical models based on a unidirectional transmission of information, from the instructor to the student. Instead, in online discussions participants constitute a community of inquiry where ideas are critically analyzed and meaning is negotiated, not blindly accepted.

Asynchronous online communication has been described as "hyperpersonal" (Walther 1996). It seems that participants feel a natural urge to reinforce the interpersonal bonds with their partners, to compensate for the intrinsic interactional limitations of the medium. To do this, participants use a wide variety of "social presence" markers (Rourke \& al. 1999), including markers of affection (emoticons, humour, self-disclosures, etc.), interactive responses (quoting others' posts, expressing (dis)agreement, 
etc.) and group cohesion expressions (vocatives, greetings, group references, etc.). Social presence markers help participants project their personalities and reinforce interpersonal bonds with each other and, most importantly, seem to be critical to online learning (Swan \& Shih 2005).

In this paper we provide a preliminary characterization of the language of asynchronous online discussions (forums) as a learning tool in higher education. Specifically, we conduct an exploratory analysis of the lexical and collocational patterns of the exchanges in a self-compiled corpus of online forums produced in a university course on translation and, by focusing on one case study, we look into the evolution of the forum messages over the time-span of the course in order to throw light on the process of acquisition of the genre by the student participants.

\section{Materials}

The context for the activity is an English-into-Spanish general (non-specialized) translation course, offered as a second-year compulsory subject for English majors at the University of Santiago de Compostela, as well as for other students taking English as a minor. The course is also very popular among international students, who constitute a significant proportion - about one third - of the participants. It is taught in the second semester, for a period of 14 weeks, and consists of 3 face-to-face lessons per week -1 expository and 2 practical lessons. The course has an accompanying Moodle-based virtual component.

Every week, one practical session is devoted to the discussion of a translation, previously done as homework by the students. This classroom discussion is then followed by a discussion online, a sort of follow-up, this time without the instructors' presence. For this purpose, between one and three weekly forums are created in Moodle, led by one student (per forum) who volunteers as a moderator. The activity develops in several stages:

1. Instructor's opening post, which includes the text excerpt to be discussed, basic instructions, deadlines and the moderator's name;

2. moderator's translation proposal;

3. classmates' comments, suggestions and general discussion;

4. moderator's improved version, summary of the main points of the discussion, response to classmates and general conclusions;

5. instructor's assessment and appraisal of the activity.

Both the nature of the event and its internal structure (at least the central elements, stages 2-4) make it similar to a cyberadvice forum (Rodríguez Muñoz 2015), where a participant presents a problem seeking advice from the community. Structurally, the events prototypically consist of a problem message (in our translation forums, the moderator's first draft), followed by an advice message (the group's suggestions for improvement), and a thanking message (the student's final response and summary). Pragmatically, advise-giving situations are particularly complex, since they involve a series of discourse actions, "a combination of assessing, judging, and directing” (Locher \& Hoffmann 2006, 71), a situation that generates a potentially face-threatening entailment of a certain asymmetry between the advice-seeker, who has a certain knowledge deficit, and the advice-giver, who takes the position of a more knowledgeable participant, one capable of giving advice.

In the translation forums analyzed for the present study, there are two participant-related factors that may impact on both the content and the language of the posts. The first one relates to the intimacy among the participants, who may hold different degrees of friendship, from being total strangers to close friends, a fact that sometimes transpires in their interventions (e.g., they tend to cite and acknowledge their close friends' contributions, while ignoring others' comments). And second, all posts are assessed by the instructors for content quality, which may generate a number of potentially conflicting functions 
in the students' minds, divided as they are between their altruistic intention to help and collaborate with their partners and their legitimate self-promotion interests.

For this study, the analyzed data comprise all the text-translation forums produced during a whole 4-month period of one of the courses. Although the language of the posts was mainly Spanish, but also Galician and, to a lesser extent, English, only the Spanish component was considered for the present analysis. A comparable corpus of forums in English as a Lingua Franca is currently being compiled, which should prove useful for future contrastive analyses. As for the language background of the forum participants, the majority were native speakers of Spanish or Galician (for whom it may be safely assumed that Spanish is their second native tongue), with 57 non-native Spanish speakers, including an overwhelming majority of Chinese and British students. Consistent with the actual gender profile of the course, female students are clearly overrepresented in our data. For convenience, Table 1 provides a summary description of the corpus profile:

\begin{tabular}{ll}
\hline Nr. of forums & $16(7$ texts) \\
\hline $\begin{array}{l}\text { Nr. of posts } \\
\text { (excluding instructors') }\end{array}$ & 940 \\
\hline Nr. of words & 164,907 \\
\hline Average nr. of words per post & 175 \\
& \\
\hline Nr. of student participants & 148 \\
\hline Language of participants & $\begin{array}{l}\text { Spanish/Galician NS: } 91 \\
\text { Spanish NNS (international students): } 57\end{array}$ \\
\hline Gender & $\begin{array}{l}\text { Female: } 110 \\
\text { Male: } 38\end{array}$ \\
\hline
\end{tabular}

Table 1: The corpus

\section{Lexical-bundle analysis}

As a first approach to the description of the genre, AntConc's Wordlist and N-gram tools were used with the whole set of texts as input in order to explore overall word frequencies and frequent word combinations which might provide a first glimpse of salient lexicogrammatical features and of the functions they serve. Among the top 60 most common items, in addition to the usual set of highly frequent grammatical words at the very top (que, $d e, l a, e n, e l$, etc.), our attention was drawn to three small subsets of elements which occur at frequencies of 200 items per 100,000 words and over, and which are revealing of the highly specific, task-oriented nature of the interactions under analysis. The first of these subsets consists of a few items whose function is basically referential and which allow the author of the message to direct the other participants' attention to the specific object of the discussion at a given point: traducción, frase, texto, palabra. Certain conjunctions expressing contrast or cause (pero, aunque, porque) also figure unsurprisingly high on the list, as they play a key role in structuring arguments and are linked to the main purpose of these interactions: setting translation options against one another and justifying personal preferences. A final group of frequently occurring items consists of elements that carry a strongly interpersonal meaning. These include personal pronouns and determiners (yo, tu, mi), references to the group (compañeros), salutations and closing words (hola, (un) saludo) and two verb forms which normally occur as part of hedging sequences (creo, parece).

As we proceed with our exploratory analysis to look at 2- and 3-gram sequences, we find very similar categories of elements among the ten most frequent lexical bundles on the list. There are referential items ( $\mathrm{mi} /$ tu/la traducción), text-structuring elements (en primer lugar, en cuanto a), elements used to connect or contrast ideas (ya que, en lugar de, en vez de), and hedges and expressions of agreement (me 
parece que, creo que, de acuerdo con). This last subset actually gains prominence as word sequences become larger and the picture gets sharper as shown in Table 2, which lists the top 40 4-gram clusters in the AntConc output ${ }^{2}$.

\begin{tabular}{ccl}
\hline Rank & Freq. & 4-gram bundle \\
\hline 7 & 90 & estoy de acuerdo con \\
8 & 72 & tu traducción me parece \\
14 & 59 & en cuanto a la \\
15 & 53 & a la hora de \\
19 & 49 & traducción está muy bien \\
20 & 48 & me parece que tu \\
22 & 46 & la verdad es que \\
23 & 45 & parece que tu traducción \\
25 & 43 & en la primera frase \\
26 & 43 & traducción me parece muy \\
27 & 43 & ya que me parece \\
28 & 41 & tu traducción es muy \\
29 & 41 & tu traducción está muy \\
30 & 40 & algunos de mis compañeros \\
32 & 40 & que tu traducción está \\
34 & 38 & yo lo traduje como \\
35 & 37 & en el texto original \\
36 & 37 & que me parece que \\
38 & 36 & me gusta mucho tu \\
39 & 36 & mi punto de vista \\
40 & 34 & creo que tu traducción \\
\hline
\end{tabular}

Table 2: 40 most frequent 4-gram bundles in the corpus

The list contains expressions that help structure the text and focus the discussion (en el caso de, con respecto a la, en la primera frase, en el texto original), but the largest proportion of items consists of sequences with a clearly interpersonal function. They serve to frame personal opinions (que me parece que, mi punto de vista), to position oneself with respect to the group (algunos de mis compañeros) or, most frequently, to show agreement and compliment the work of other participants, in particular of the forum moderator (estoy de acuerdo con, tu traducción me parece, traducción está muy bien, me gusta mucho tu, etc.). Such expressions play a key role as politeness devices to mitigate critical comments, but they also help create a warmer learning environment and enhance group cohesion. Their presence may therefore be expected to evolve over the time span of the course, as (or if) the group develops into a genuine community of inquiry.

2 The missing items, as indicated by rank order numbers, correspond to highly frequent chunks of internet addresses which have been cleared away. 
With the aim of exploring the development of this interpersonal dimension over time, the corpus was split into three roughly equal time periods and occurrences of some of the most explicitly complimentary expressions were counted in each of these subcorpora. Normalized frequencies (per 100,000 words) are shown as Figure 1.

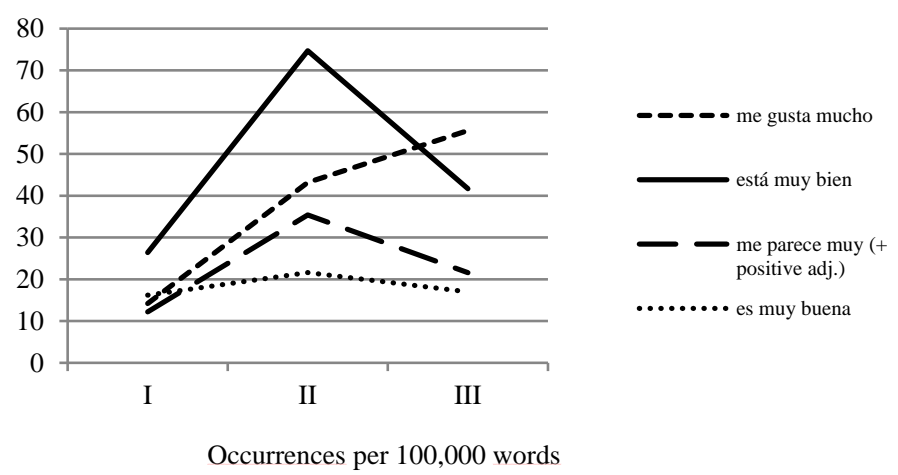

Figure 1: Distribution of four complimentary sequences over time

The overall frequency of these clusters clearly increases over the whole term, although it is also noticeable that their presence rises rather sharply about one and a half months into the course and tends to level off or even drop significantly towards the end. This pattern is actually consistent with findings reported in other studies of online asynchronous interaction, where it was found that "as [students] begin to feel more comfortable with the online discussion, the explicit personal recognition appears to drop" (Akyol \& Garrison 2014, 16). In order to be able to interpret these changes over time as evidence of development of a sense of community, we need to adopt a more qualitative approach, where the cooccurrence of several of these features is analyzed in context. Such is the end of the following section, where the contributions of a representative individual are tracked over the whole time span of the course.

\section{A case study}

In general, there seems to be an evolution in the nature of the posts throughout the course, from a rather tentative, author-centered, mostly informational type of message to a progressively longer one with a more complex structure, and especially, as revealed by the lexical-cluster analysis in the previous section, a heightened awareness of the dialogic and multi-party nature of the exchanges. This is reflected in the increasing use of "social presence" markers, which, as stated in the introduction, are critical for online learning (Rouke et al., 1998; Garrison 2003). The observed changes reflect an increased sensitivity to the importance of the interpersonal relationships with the other participants: over time, the conception of the posts in the students' practices evolves from a mere exchange of information to a complex meaning negotiation where projecting an appropriate self-image and showing concern for the image of other individuals and of the group are crucial to the success of the exchange and, therefore, play an increasingly bigger part in the students' interventions.

We will illustrate this by providing an in-depth analysis of a sample of the contributions of one of the student participants at the beginning, midterm and end of the course. As expected, students differed greatly as to their degree of commitment to the task: some participated occasionally or not at all, while others contributed to almost all the forums with very elaborate posts. Our subject is representative of the average student, in terms of gender (female), participation frequency and quality: the length of her interventions, in particular, follows the general pattern, starting off with rather simple, short posts that 
become longer and more complex in midterm before decreasing slightly in size towards the end of the period.

On week 1, her contributions consist in a mere sequence of proposals and the accompanying justifications. Personal references are restricted to the first person author. There is little interpersonal work, but for the use of repeated standard hedges, such as verbs in the conditional (traduciría, reformularía, "I would translate/reformulate", etc.), and other epistemic expressions (creo que, "I believe that"), although occasionally we find some barely mitigated directives (debe colocarse, "must be used"), showing little consideration for the moderator's (and the group's) negative face.

\section{Week 1 - Excerpt 1}

Yo traduciría "a glass of iced" como una "taza" y no "vaso", porque creo que queda mejor en el contexto. Reformularía la frase siguiente puesto que...

\section{Week 1 - Excerpt 2}

Hay varias cosas que creo que podrían mejorarse. Primero, tras las preguntas, si hay un verbo aclarativo, debe colocarse una coma.

By week 5, one month into the term, the posts have become more dialogic, showing a moderate increase in the frequency of social presence markers. The post now opens with a salutation followed by an exclamation mark (Hola!), which signals the poster's intention to infuse some human warmth into the text. For the first time, she makes explicit references to the group (mis compañeros, "my classmates"), individual participants are identified by their first names (Elena) and several attempts are made to create solidarity with other participants by aligning with their opinions and acknowledging their contributions (como bien te han dicho, "as they have rightfully pointed out").

Week 5 - Excerpt 3

\section{Hola!}

En primer lugar, como bien han mencionado ya algunos de mis compañeros, yo tampoco optaría por emplear el verbo "reforzar" como traducción a "bolster". En mi caso he optado por el verbo " alentar". También estoy de acuerdo con Elena y no deberías omitir la referencia a que Bruselas es la capital de Bélgica... Y como bien te han dicho, el equivalente a "dutch" es el idioma flamenco o neerlandés.

By week 12, almost at the end of the term, the student's posts have definitely become more complex and more dialogic in nature, containing a much wider variety of social presence manifestations. The post opens with a personal salutation that mentions the addressee (forum moderator) by his first name. She then starts by openly praising the moderator's proposal (me gusta mucho, "I like it a lot"), to be followed by a sort of personal narrative (he hecho una breve búsqueda - "I did some research") that includes a self-confession (se me ha atragantado un poco - "I got a bit stuck") about the difficulties caused by the task (i.e. recognition of problems). Such self-disclosures, as suggested by some CMC specialists (Rourke et al., 1999), present the poster in a more human guise, provide emotional satisfaction, invite reciprocating, create trust and, therefore, readiness to collaborate. The post ends with a highly-interative and polite manifestation of other-interestedness (gift-giving) before the final farewell.

Week 12 - Excerpt 4

\section{Hola Daniel,}

Me gusta mucho cómo has hecho esta parte de la traducción, que a mi alguna que otra frase se me ha atragantado un poco. (...) he hecho una breve búsqueda y 
hablando en términos geográficos el continente es América (...) Te dejo aquí un enlace de la wikipedia donde puedes leer más sobre esto (...)

\section{Un saludo!}

In sum, our short case study shows a clear change in this particular student's discourse practices over the course of the term, who progressively incorporates new functions into her posts, resulting in rather more complex texts by the end of the period. The most striking difference relates to the substantial increase in the use of social presence markers, which, for many, are "an important factor in the success of online learning” (Swan \& Shih 2005, 116). More generally, the observed changes seem to reflect an underlying process of collective construction/acquisition of a new genre by the students. Instructors play a significant role in this acquisition, by sanctioning good practices and providing general guidelines; but, arguably, so do specific individual students, who act as transmission belts for the instructors' ideas, introducing their own innovations and behaving as models for the rest of the group. Of course, this is a major claim that needs to be substantiated by further research.

\section{Concluding Remarks}

Online discussion forums are a powerful pedagogical tool and a valuable complement to class sessions. They define a shared learning space that encourages deeper reflection and further elaboration of thoughts and ideas. Interaction through the forum helps develop a sense of community and facilitates collaborative learning. The narrowly defined, task-oriented nature of these forums results in an extremely high frequency of characteristic lexical patterns, which are, however, far from stable over the time span of a single term. In particular, the consistent increase in the frequency of social presence markers is evidence of an enhanced sense of group membership towards the end.

A case study analysis shows a clear evolution in the student's posts, which reflects an interesting process of acquisition/honing of the tool by the whole community so as to better fulfill their goals. Further corpus work is needed on a wider set of lexicogrammatical features to enrich our knowledge of this process, but a more qualitative approach will also be necessary to explore the roles that individual participants play in the development, transmission and consolidation of some of the observed patterns.

\section{References}

Akyol, Z., \& Garrison, D. R. (2014). The development of a community of inquiry over time in an online course: Understanding the progression and integration of social, cognitive and teaching presence. Journal of Asynchronous Learning Networks, 12(3-4), 3-22.

Biber, D., \& Conrad, S. (2009). Register, Genre and Style. Cambridge: Cambridge University Press.

Condon, S. L., \& Čech, C. G. (2010). Discourse Management in Three Modalities. Language@Internet, 7, 1-32.

Garrison, D. R. (2003). Cognitive presence for effective asynchronous online learning: the role of reflective inquiry, self-direction and metacognition. In Elements of Quality Online Education: Practice and Direction (pp. 47-58). Sloan Center for Online Education.

Herring, S. C. (1999). Interactional coherence in CMC. Journal of Computer Mediated Communication, 4: 0. doi:10.1111/j.1083-6101.1999.tb00106.x

Ho, C. H., \& Swan, K. (2007). Evaluating online conversation in an asynchronous learning environment: An application of Grice's cooperative principle. Internet and Higher Education, 10(1), 314. 
Locher, M. A., \& Hoffmann, S. (2006). The emergence of the identity of a fictional expert advicegiver in an American Internet advice column. Text and Talk, 26(1), 69-106.

Rodríguez Muñoz, F. J. (2015). Análisis discursivo del ciberconsejo en el género foro virtual de discusión. Revista Española de Lingüística Aplicada, 28(2), 486-510.

Rourke, L., Anderson, T., Garrison, D. R., \& Archer, W. (1999). Assessing Social Presence In Asynchronous Text-based Computer Conferencing. Journal of Distance Education, 14(2), 50-71.

Swan, K., \& Shih, L. F. (2005). On the nature and development of social presence in online course discussions. Journal of Asynchronous Learning Networks, 9(3), 115-136.

Walther, J. B. (1996). Computer-Mediated Communication: Impersonal, Interpersonal, and Hyperpersonal Interaction. Communication Research, 23(1), 3-43. 